\title{
LA PALABRA ANTIGUA Y NUEVA DEL HOMBRE DE MESOAMERICA
}

\author{
POR \\ MIGUEL LEON-PORTILLA \\ Universidad Nacional Autónoma de México
}

Como en otros lugares del Viejo Mundo, también en Mesoamérica (centro y sur de México, Guatemala, Belice, El Salvador, Honduras, Nicaragua y parte de Costa Rica) floreció, a través de milenios, una alta cultura. Entre sus creaciones más sobresalientes están sus centros religiosos, con templos, esculturas y pinturas murales extraordinarias. Los orígenes de la alta cultura mesoamericana se sitúan hacia mediados del segundo milenio antes de Cristo. A partir de entonces, los olmecas - gentes de la región del «hule» o caucho- empezaron a desarrollar sus creaciones a lo largo de las costas del golfo de México, en el área limítrofe de los actuales estados de Veracruz y Tabasco.

Las transformaciones olmecas, de las que dan testimonio los hallazgos arqueológicos, presuponen considerable incremento en la población, con nuevas estructuras económicas, sociales, políticas y religiosas. De la «cultura madre» olmeca habría de derivarse el nuevo florecimiento del llamado período clásico, cuyos comienzos coinciden aproximadamente con los de la era cristiana. Nacen entonces las ciudades en Mesoamérica: Teotihuacán, que, hacia el siglo IV d. C., alcanzó una población de cerca de 80.000 habitantes, así como otras muchas urbes, sobre todo en el ámbito de Oaxaca y en la gran zona mayense.

A1 acercarnos ahora a la herencia de cultura mesoamericana -que comprende sus múltiples monumentos, cuanto ha descubierto la arqueología, desde el preclásico con los olmecas (1500-100 a. C.), el clásico (100 a. C.-850 d. C.) y el posclásico, hasta la Conquista en $1521-$ queremos atender aquí a otro de sus logros más sofisticados: el de la transmisión de su palabra. Ello ocurrió, primero, a través de textos en inscripciones, muchas veces con anotaciones calendáricas, y luego en sus libros con pinturas y glifos, «sus códices», sin excluir la tradición oral 
sistemática, comunicada en sus escuelas, de las que nos hablan los cronistas.

Mi intención es ofrecer en esta Revista, dedicada a la literatura iberoamericana, una introducción no ya sólo a la producción literaria de Mesoamérica prehispánica, sino también nuevos testimonios de la perduración y enriquecimiento modernos de la que he llamado «antigua palabra». El propósito es mostrar que, a casi medio milenio del contacto hispano-indígena, la expresión creadora del hombre mesoamericano, lejos de haber muerto, experimenta en la actualidad un resurgimiento.

\section{Los MÁs antiguos vestigios de la palabra de MEsoAméRICA}

Haciendo abstracción de los signos — isímbolos o glifos? - que acompañan a numerosas esculturas, bajo relieves y otras producciones del área olmeca, tomaré como punto de partida las inscripciones que se conservan de la primera etapa de Monte Albán -el gran centro zapoteca en Oaxaca- de cerca del 600 a. C. Allí, en las llamadas «estelas de los danzantes», están los primerísimos mensajes escritos, prenuncio de la expresión de la palabra indígena. Esas inscripciones incluyen registros de años y días, numerales, nombres de lugar, de caudillos y dioses, señalamientos de conquistas y de portentos divinos.

Mencionando sólo algunos otros de los más importantes conjuntos de inscripciones, recordaré las que aparecen en el montículo $\mathrm{J}$, también de Monte Albán (cerca del 300 a. C.); la llamada estela C de Tres Zapotes (Veracruz), con la fecha de 31 a. C. A partir luego de los tiempos que coinciden ya con la era cristiana, se inicia el horizonte clásico de los zapotecas, en Oaxaca; los teotihuacanos, en el altiplano central; los mayas, en las tierras bajas de Chiapas, Guatemala, Yucatán, y de otros grupos a lo largo de las costas del Golfo y del Pacífico. En sus grandes centros, al lado de los templos, aparecen las inscripciones en monumentos, estelas, dinteles, escalinatas, objetos de cerámica.

En Oaxaca, los jeroglíficos acompañan conjuntos de imágenes, que ostentan un carácter narrativo o de representación de sucesos. De este sistema de escritura se derivaron luego los de los pueblos del altiplano central (teotihuacanos, xochicalcas, toltecas, aztecas o mexicas) y asimismo el de los mixtecas de Oaxaca y áreas cercanas. Evolución diferente fue la de los mayas. Su escritura, mucho más compleja, alcanzó mayor precisión y versatilidad. Sus glifos se combinan entre sí dando lugar a estructuraciones que connotan diversos géneros de ideas. En los últimos 
tiempos se ha avanzado en el desciframiento de la escritura maya. Sabemos que tiene un carácter en parte ideográfico y en parte fonético o evocador de sonidos.

\section{LoS LIBROS Y LA TRADICIÓN ORAL EN MESOAMÉRICA}

También hubo libros o «códices», elaborados unas veces en piel de venado y otras en papel preparado a partir de la corteza machacada del amate (un ficus) o con la fibra del maguey (un agave). Las «páginas» de estos libros se doblaban sin separarse unas de otras, a manera de biombos, con tamaños y formatos diferentes. Aunque a raíz de la Conquista se destruyeron muchos de tales libros, se conservan tres de origen maya prehispánico; seis, también prehispánicos, de la región central, y siete más del área de Oaxaca. Son éstos los libros más antiguos del Nuevo Mundo. De ellos hay uno, el manuscrito maya Tro-Cortesiano o de $\mathrm{Ma}$ drid, en el Museo de América de la capital de España. Otro de los códices mayas - todos ellos astronómico-astrológico-rituales- se conserva en París y uno más en Dresde. De los seis provenientes del altiplano central de México — también rituales y astrológicos-, algunos fueron a dar a Italia (Vaticano y Bolonia), otros a Inglaterra (Oxford y Liverpool) y uno más a Viena. Parecido fue el destino que corrieran los libros mixtecos de contenido histórico. Sólo uno quedó en México —el llamado hoy Colombino_, en el Museo Nacional de Antropología. En forma más amplia, puede decirse de estos códices y de otros, bastante numerosos, que se continuaron elaborando en los años que siguieron a la Conquista; que su contenido abarca cómputos calendáricos, relatos históricos, tablas de eclipses, información acerca de las creencias religiosas, las fiestas y los ritos ${ }^{1}$.

Los códices tuvieron un complemento de enorme importancia en los textos, que, muchas veces como comentario, se componían y memorizaban de modo sistemático en las escuelas anexas a los templos. Así, por el triple camino de las inscripciones en los monumentos, de los glifos e imágenes en los códices y de la comunicación oral de los textos, se transmitió y perduró en el México antiguo la palabra, belleza y sabiduría en su expresión cuidadosa. Al ocurrir el encuentro, hace cerca de quinientos años, así como muchos se afanaron en destruir la expresión indígena, tenida

'Véase Miguel León-Portilla, Toltecáyotl, aspectos de la cultura náhuatl (México: Fondo de Cultura Económica, 1980), pp. 53-135 y 437-445. En este libro describo y analizo con cierta amplitud un conjunto de fuentes mesoamericanas, códices y textos de origen prehispánico. 
como inspirada por el demonio, hubo también otros -humanistas extraordinarios como Bernardino de Sahagún- que se empeñaron en rescatar la sabiduría de Mesoamérica. También hubo indígenas que siguieron pintando y escribiendo otros manuscritos, en sus varias lenguas nativas. De este modo, a pesar de la quema de muchos códices, ocurrió también un rescate de testimonios de la tradición mesoamericana. Estudiando los códices que se conservan, acercándonos a las inscripciones jeroglíficas y asimismo, de modo muy particular, traduciendo los textos en los que, desde principios del siglo XVI, valiéndose ya del alfabeto, se puso por escrito la «antigua palabra», es como podemos presentar y valorar este gran conjunto de producciones literarias de Mesoamérica. Las principales lenguas en que están ellas expresadas son el náhuatl (empleado por teotihuacanos, toltecas, mexicas o aztecas y por otros pueblos), el maya-yucateco, el quiché, el cakchiquel, el mixteco, el otomí...

\section{LA NUEVA PALABRA CON RAÍCES EN EL VIEJO LEGADO}

Contra lo que muchos pensaron y llegaron a proclamar - una decadencia total de las culturas indígenas, sin capacidad ya de expresión-, es un hecho que, sobre todo, desde hace un par de décadas, la vieja sabiduria ha comenzado a manifestarse de nuevo. Afanes de autoafirmación étnica han llevado a la recordación de antiguas formas de experiencia. Historia y pensamiento ancestrales se asoman en nuevos géneros de relatos, discursos, invocaciones, poemas y cantos. La pasmosa maravilla de un resurgir en la expresión literaria de gentes de Mesoamérica -a casi cinco siglos de la Conquista- se perfila como incipiente realidad.

Desde luego, en la «nueva palabra» no todo es evocación de los mitos y leyendas primordiales. Hay creaciones auténticamente modernas, con temas que atañen al ser de personas y comunidades contemporáneas. Para documentar esta afirmación citaré tres casos de particular interés. Es el primero el de un grupo de personas de idioma nahua, del área de Hueyapán, en el estado de Puebla. Para fomentar la creatividad literaria en su lengua han instuituido un "Premio Nacional», que se otorga cada año a las mejores composiciones en prosa y verso. Algunas de las obras que así se han presentado son en verdad significativas ${ }^{2}$.

${ }^{2}$ Varios de los relatos enviados al concurso fueron transcripciones de la tradición oral con raíces muy antiguas, incluso, en dos o tres casos, con mitos y leyendas del pasado prehispánico. En otros casos las composiciones fueron fruto de la inventiva espontánea de sus autores. En ese primer concurso obtuvo el Premio Nacional un maestro normalista, Delfino Hernández, oriundo de Chicontepec, Veracruz, y 
Caso diferente es el de un grupo de habla zapoteca, que tiene como centro a Juchitán, en el istmo de Tehuantepec, en Oaxaca. Allí el cultivo de una moderna literatura zapoteca es una realidad patente no sólo en festivales y transmisiones radiofónicas, sino también en publicaciones periódicas y eventuales ${ }^{3}$.

De otros varios casos que podrían citarse aludiré sólo a la celebración de «talleres de capacitación de escritores» en lenguas de Mesoamérica, que, desde 1970, se han llevado a cabo, con el patrocinio del Instituto Lingüístico de Verano y, en algunos casos, también con el de diversas entidades que forman parte de o colaboran con la Secretaría de Educación Pública, como la Dirección General de Culturas Populares y el Instituto Nacional Indigenista. Resultado de la labor de esos talleres son varios centenares de publicaciones - genuinas obras literarias - en lenguas como el otomí, tzeltal, mixteco, náhuatl, maya, zapoteco, huaxteco y otras ${ }^{4}$.

cuya lengua materna es el náhuatl de la Huasteca. Su obra, publicada en un periódico de circulación restringida (Ixtoc, 2 de diciembre de 1982, p. 5), se intitula Xochitaitouani, literalmente «el que habla con flores».

Prueba del interés por mantener la continuidad de estos certámenes la da el hecho de que para el año 1983 se ha hecho circular nueva convocatoria. Hasta la fecha (15 de agosto de 1983), al decir de los organizadores, se ha recibido ya una veintena de producciones literarias.

${ }^{3}$ Entre la serie de publicaciones que incluyen muestras de la literatura zapoteca contemporánea citaré las siguientes: Víctor de la Cruz, La flor de la palabra. Antología de la palabra (Juchitán, Oaxaca, 1983). La revista Guehachi 'Reza, de la que han aparecido varios números, en casi todos los cuales se incluyen poemas, canciones y relatos en zapoteca con su correspondiente traducción. La revista Tequio, publicada asimismo en Juchitán, Oaxaca. También en ella la mayor parte de sus colaboradores presentan sus creaciones en zapoteca y en castellano.

${ }^{4}$ El Instituto Lingüístico de Verano (México) ha publicado una Bibliografía de los materiales escritos por autores autóctonos (México, 1973, 38 págs.). En ella se registran más de cuatrocientos trabajos en las siguientes lenguas: chol, lacandón, tojalabal, tzeltal, tzotzil, zoque, maya yucateco (todas éstas de la familia mayense); tarahumara, tepehuán, cora, náhuatl (todas del tronco lingüístico yuto-azteca); amuzgo, mixteco, tlapaneca, otomí, mazahua, cuicateco, chontal, trique y zapoteco (todas del tronco lingüístico macro-otomangue); tarasco (lengua única en su familia); seri (del tronco hokano). Véase asimismo Ascensión H. de León-Portilla, «Publicaciones sobre lengua y literatura nahuas», en Estudios de Cultura Náhuatl (México: UNAM, Instituto de Investigaciones Históricas, 1982), vol. 15, pp. 291-296. Hace allí el registro de varios trabajos obra de autores indígenas. Puede consultarse también: Catálogo general de ediciones, 1976-1982 (México: Dirección General de Culturas Populares, 1982, 46 págs.). Incluye bibliografía y descripción de numerosas publicaciones en varias lenguas indígenas. Relación bibliográfica de Acayucan (México: Dirección General de Culturas Populares, 1982), p. 100. Ofrece referencias bibliográficas, con breve descripción, de más de trescientos textos en una de las siguientes lenguas: zoque (municipio de Soteapan, Veracruz), popoloca zoqueano (municipios de So- 
En la presente introducción a lo que he intitulado «la palabra antigua y nueva del hombre de Mesoamérica» aduciré sólo unas pocas muestras -inevitable limitación de espacio- de testimonios de la expresión prehispánica, acompañadas de otros tantos ejemplos afines de la palabra nueva. Los temas escogidos son: 1) Los dioses-días; 2) El origen del maíz; 3) Himnos al Dador de la lluvia; 4) El águila de la nación azteca, y 5) El árbol sagrado de donde provienen los mixtecas.

\section{LOS DIOSES-DÍAS}

En el pensamiento mesoamericano, cada una de las divisiones del tiempo tiene su propia carga de símbolos sagrados. Las cuentas de años, de las veintenas y de los ciclos de cincuenta y dos años y también las veintenas y treintenas de días, las trece divisiones del día y las nueve de la noche, además de ser portadoras de un destino que afecta a los seres humanos de múltiples formas, se identifican con su correspondiente deidad, de tal suerte que todas las fechas de las cuentas calendáricas incluyen entre sus connotaciones la de ser el nombre de un dios. En tal sentido, tanto en el área mayense como en la de Oaxaca, en el altiplano central y en el resto de Mesoamérica, encontramos que se menciona a veces a los dioses con su nombre calendárico. Así, por ejemplo, Macuilxóchitl (el del siglo 5-Flor) no es otro sino el dios de la poesía, la danza y la música; Nahui-ollin (el del siglo 4-Movimiento) corresponde a la deidad solar, que precisamente comenzó a resplandecer en tal fecha.

Aquí transcribo la versión de un texto maya de la tradición prehispánica y también el fragmento de otro recogido hacia 1960. El primer texto es de los mayas de Yucatán. El segundo pertenece a la palabra viva de indígenas chuj del Departamento de Huehuetenango en Guatemala. Veamos lo que expresó en su viejo manuscrito el Chilam Balam de Chumayel (el «Sacerdote Jaguar», del pueblo de Chumayel, en Yucatán) sobre lo que ocurrió cuando, por vez primera, la veintena de días se integró y nació el ciclo del uinal, «mes de veinte días» de los mayas.

teapan y Texistepec, Veracruz), nahua-pipil (municipios de Mecayapan, Santiago. Tuxtla y otros), mixe (grupo al oeste de Acayucan) y chontales de Tabasco (grupo mayense, al norte de la ciudad de Villahermosa, Tabasco). 


\section{La palabra del Chilam Balam, 'Sacerdote Jaguar'}

Así explicó el gran sabio, el primer profeta Napuctún, primer sacerdote solar, así es la canción.

Sucedió que nació la veintena de días, allí donde no había despertado la tierra, antiguamente.

Y empezó a caminar por sí misma...

$Y$ se explica que haya nacido porque sucedió que Oxlahun $O c$, 'El de los trece pies', emparejó su pie.

Partieron del oriente.

$Y$ se dijo el nombre del día, allí donde no lo había antiguamente...

Así nació la veintena de días y nació el nombre del día y nacieron el cielo y la tierra, la escalera del agua, la tierra, las piedras y los árboles, nacieron el mar y la tierra.

El 1-Chuen (1-Artífice) sacó de sí mismo su divinidad, hizo el cielo y la tierra.

E1 2-Eb (2-Niebla) hizo la primera escalera y bajó su divinidad en medio del cielo, en medio del agua, donde no había tierra, ni piedra, ni árbol.

El 3-Ben (3-Raíz) hizo todas las cosas, la muchedumbre de las cosas, las realidades de los cielos, del mar y de la tierra. E1 4-Ix (4-Jaguar) sucedió que se encontraron, el cielo y la tierra, inclinándose.

E1 5-Men (5-Mujer artista) sucedió que todo trabajó, el 6-Cib (6-Cera) sucedió que se hizo la primera luz, donde no había sol ni luna.

El 7-Caban (7-Movimiento de tierra) nació por primera vez la tierra donde no había nada para nosotros antiguamente. 
El 8-Etznab (8-Pedernal) asentó su mano y su pie que clavó sobre la tierra.

E1 9-Cauac (9-Relámpago) ensayó por primera vez los mundos inferiores.

E1 10-Ahau (10-Señor) sucedió que los perversos

se fueron a los mundos inferiores...

E1 11-Imix (11-Gran Ser Terrestre) sucedió

que modeló piedra y árbol,

lo hizo así dentro del sol.

El 12-Ik (12-Viento) sucedió

que nació el viento

y así se originó su nombre,

viento, espíritu,

porque no había muerte dentro de él.

En el 13-Akbal (13-Noche) sucedió que se tomó agua,

se humedeció la tierra

y se modeló el cuerpo del hombre...

Así nació la veintena de días

y sucedió que despertó la tierra,

aparecieron el cielo y la tierra

y los árboles y la piedra...

La lectura de la cuenta de los días.

uno antes que el otro,

empieza por el oriente...5

La aparición sucesiva de los dioses-días trajo consigo la existencia del cielo y la tierra y de todo cuanto se mira en los cuatro rumbos del mundo. El hombre sabe que los dioses-días son portadores de su propio destino. Por eso debe propiciarlos, inquiriendo, por medio de su calendario, acerca de su llegada y de la de todas las otras deidades el tiempo. Esta creencia, que fue clave en la cosmovisión de los antiguos mayas, perdura de algún modo, como lo muestra el siguiente texto de los chuj, transcrito hacia 1960, en Huehuetenango, Guatemala.

\section{La voz viva en relación con los dioses-días}

Y también hay otros dioses,

que son los momentos del tiempo.

Hay veinte dioses-días que nos miran cada día.

Un dios-día nos contempla cada día.

${ }^{5}$ Chilam Balam de Chumayel. Texto maya en Ralph L. Roys, The Book of ChiIam Balam of Chumayel (Carnegie Institution of Washington, 1933), pp. 38-39. 
Por esto nosotros alimentamos a estos dioses-días.

Si no les damos de comer, su corazón se disgusta con nosotros.

Estos dioses-días tienen el mismo poder que el Sol, nuestro dios.

Por eso es necesario que también alimentemos a los dioses-días,

fijemos nuestro pensamiento en ellos.

Si dejamos de alimentar a los dioses-días,

hay veces que cuando caminamos,

cuando andamos para ir a nuestro trabajo,

la serpiente nos saldrá a encontrar.

Es servidora de los dioses-días.

Porque el corazón de éstos no está satisfecho, porque no los servimos,

ella, la serpiente, mensajera de ellos,

nos resulta provechosa.

De este modo arreglamos nuestra vida,

así no moriremos...

Todas esas cosas son acompañantes,

todas son dioses,

las cosas de madera, las cruces,

realmente son nuestros dioses,

porque allí es donde viven los dioses-días.

Por eso es necesario que tengamos mucho cuidado de ellas,

que les tengamos respeto.

Esas cosas son muy grandes, mucho significan.

Nuestros antepasados dijeron

que debemos ofrecerles sacrificios.

Hay trece formas de sacrificios.

Hay también algunos sacrificios que sólo son cuatro.

Hay otros que sólo son ocho.

Debemos obedecer esto...

Por esto os digo todo esto,

son cosas muy importantes.

No dejéis que esto se pierda,

porque todo ello es realidad viviente.

Vive con los dioses-días

y con el Dios día-noche.

Siempre están ellos

en unión con el Sol, nuestro Dios ${ }^{6}$.

\footnotetext{
${ }^{6}$ "Los dioses de los chuj». Texto en lengua chuj recogido por K. Williams hacia 1960, en Huchuetenango, Guatemala. Archivo del Instituto Linguiístico de Verano, México, D.F.
} 


\section{EL ORIGEN DEL MAÍZ}

Cereal americano por excelencia es el maíz. Altamente probable parece que su primera domesticación haya ocurrido en Mesoamérica. De hecho, en varios sitios del territorio mexicano se han hallado los vestigios más antiguos de este cereal y otras semillas, como en la cueva de Cozcatlán, en el actual estado de Puebla, con una antigüedad cercana a los 5000 a. C. En la rica mitología de los hombres, que, según sus creencias originales, fueron hechos de maíz, el tema tiene obvia y primordial importancia. Dos textos presentaré aquí. Uno, de la tradición prehispánica, en lengua náhuatl, de los mexicas o aztecas. El otro, recogido en la década de 1970 entre los tzeltales, grupo mayense que vive en el actual estado de Chiapas, en México. Tema de uno y otro relato es el redescubrimiento del maíz en la actual edad del mundo, ya que, por varias razones, el preciado cereal había quedado oculto bajo una roca en el «Monte de nuestro sustento». En el texto prehispánico interviene Quetzalcóatl, el dios sabio y benévolo. En el recogido de la voz viva son los ancianos, los antepasados, los que actúan. En ambos casos, las hormigas, el rayo y el trueno tienen papel decisivo.

El descubrimiento del maíz, texto náhuatl de la tradición prehispánica

Así pues, de nuevo dijeron los dioses:

- ¿Qué comerán los hombres, oh dioses?, ique descienda el maíz, nuestro sustento!

Pero entonces la hormiga va a coger el maíz desgranado, dentro del Monte de nuestro sustento. Quetzalcóatl se encuentra a la hormiga, le dice:

— ¿Dónde fuiste a tomar el maíz?, dímelo.

Mas la hormiga no quiere decírselo.

Quetzalcóatl con insistencia le hace preguntas.

Al cabo dice la hormiga:

-En verdad allí.

Entonces guía a Quetzalcóatl, éste se transforma en seguida en hormiga negra. La hormiga roja lo guía, 
lo introduce luego al Monte de nuestro sustento.

Entonces ambos sacan y sacan maíz.

Dizque la hormiga roja

guió a Quetzalcóatl

hasta la orilla del monte,

donde estuvieron colocando el maíz desgranado.

Luego Quetzalcóatl lo llevó a cuestas a Tamoanchán.

Allí abundantemente comieron los dioses,

después en nuestros labios puso maíz Quetzalcóatl,

para que nos hiciéramos fuertes.

$\mathrm{Y}$ luego dijeron los dioses:

- ¿Qué haremos con el Monte de nuestro sustento?

Mas el monte allí quiere quedarse,

Quetzalcóatl lo ata,

pero no puede moverlo.

Entre tanto echaba suertes Oxomoco,

y también echaba suertes Cipactónal,

la mujer de Oxomoco,

porque era mujer Cipactónal.

Luego dijeron Oxomoco y Cipactónal:

-Tan sólo si lanza un rayo Nanáhuatl, quedará abierto el Monte de nuestro sustento.

Entonces bajaron los tlaloques [dioses de la lluvia], los tlaloques azules,

los tlaloques blancos,

los tlaloques amarillos,

los tlaloques rojos.

Nanáhuatl lanzó en seguida un rayo, entonces tuvo lugar el robo

del maíz, nuestro sustento,

por parte de los tlaloques.

El maíz blanco, el oscuro, el amarillo,

el maíz rojo, los frijoles,

la chía, los bledos,

los bledos de pez,

nuestro sustento,

fueron robados para nosotros?

${ }^{7}$ Leyenda de los Soles, texto de la tradición prehispánica reducido al alfabeto en 1558. Copia del mismo se conserva en el folio 77 del llamado Códice Chimalpo. ca. Archivo del Museo Nacional de Antropología, México. Versión al castellano de Miguel León-Portilla. 
Si en el texto de la tradición prehispánica es Quetzalcóatl quien fue en busca del maíz, en cambio, en el relato de los tzeltales, son ancianos de tiempos muy antiguos los que, al ver que la hormiga sabía dónde estaban las anheladas semillas, entran también en una especie de alegato con ella. Una vez descubierta la roca o monte que esconde el maíz, surge el mismo problema: ¿cómo abrirlo, cómo penetrar allí para adueñarse de lo que buscan?

Al igual que en el relato náhuatl prehispánico, también en el de los tzeltales entran en juego el relámpago y el rayo. Pero la tradición tzeltal incluye un nuevo elemento: el pájaro carpintero que -extraña curiosidad-, ia sugerencia de unos judíos!, es traído para que, con su pico, encuentre el lugar donde la roca es más delgada. Al fin, el rayo y el relámpago rojo parten en dos la roca. El maíz volvió a quedar entonces al alcance del hombre. En lo esencial, a cerca de quinientos años de distancia de que se recogió la tradición prehispánica, la palabra de los tzeltales conserva como parte de sus creencias el mismo mito con unas pocas variantes.

\section{El origen del maíz según los tzeltales contemporáneos}

Te voy a decir otra cosa. La oí. Los ancianos hace mucho me la contaron. Ellos decían así: De este modo apareció la primera semilla de nuestro maíz. Allí estaba una hormiga negra grande, como las que vemos que andan y hacen sus casas en la tierra. La hormiga llevaba a cuestas maíz. Cuando ellos vieron que era maíz lo que llevaba a cuestas, la agarraron. Le preguntaron dónde cogía el maíz. Entonces la amarraron, la apretaron mucho por el medio.

-Si no dices dónde consigues el maíz, te apretaré tanto hasta que. tu estómago se parta en dos, así le dijeron.

-Aun así, no les diré dónde lo consigo, respondió ella. No fue sino hasta que la apretaron mucho, sintió ella que su estómago se estaba partiendo en dos, dijo dónde conseguía el maíz.

-Es inútil, ¿cómo podrán ustedes conseguir el maíz?, porque está en una roca, dijo. $Y$ porque yo soy pequeña, por eso puedo entrar allí, dijo.

- Pero será bueno que nos muestres dónde está, le dijeron.

Luego la hormiga se va. Entra por la orilla de la roca y sacó una semilla de maíz. La tenía al salir.

-Bien, porque has mostrado dónde estaba el maíz, está bien, te: libraremos, así le fue dicho. De este modo la hormiga quedó libre. Poresto vemos que su estómago está casi partido en dos. 
Cuando ya vieron los antiguos dónde estaba el maíz, bien dijeron:

- ¿Qué haremos, porque está bajo una roca?

Esto es lo que dijeron hace mucho tiempo los judíos, de acuerdo. con su palabra: - Será bueno ir a traer un pájaro carpintero, puesto. que él podrá golpear la roca; así oiremos en qué parte está más delgada.

El pájaro, que han visto ustedes, el pájaro carpintero, así se le llama. Se le hizo venir. Cuando llegó, se le dijo que golpeara la roca. El no quiso porque su cabeza le dolía y, si golpeaba con su pico, comería con dificultad.

Por esto, le dijeron: -No te entristezcas, se te cambiará tu pico, así éste será muy fuerte. De este modo el pico del pájaro fue cambiado, se le encajó, se le amarró en su cabeza y, si ustedes se fijan al verlo, examinen la cabeza del pájaro, allí aparece como que está amarrado el pico. Cuando su pico quedó puesto, golpeó la roca para encontrar en dónde estaba más delgada. A1 fin lo encontró.

Entonces ese lugar comenzó a ser también golpeado por el Rayo. Algunas gentes tienen al Rayo como nagual (alter ego). Y cuando los dos (el pájaro y el Rayo) no podían lograr lo que buscaban, vino un tercero, el que se llama Relámpago rojo. Pegó contra la roca y ésta se rompió.

Allí había maíz amontonado y el que rompió la roca, murió del esfuerzo. Luego los judíos, en seguida juntaron las semillas grandes de maíz, las escondieron.

Y cuando revivió el Relámpago rojo, preguntó: - ¿Era solamente éste el maíz que allí había?

- Sólo era éste el que allí había, contestaron los judíos. Está bien, empezaron entonces a contarlo entre ellos. Luego fueron a plantar el maíz...8

\section{Himnos al DADOR DE LA LluVia}

En Mesoamérica tan primordial ha sido la importancia del maíz, «nuestro sustento», como la del líquido precioso - jade portador de la vida- que fertiliza a las plantas. No es extraño, por consiguiente, que se desarrollara a lo largo de los siglos un gran conjunto de creencias y ritos para propiciar al dios o dioses dadores de la lluvia. En algunos himnos sagrados de los pueblos de idioma náhuatl se hace invocación de

${ }^{8}$ Texto recopilado y transcrito en tzeltal de la región de Bachajón, en el estado de Chiapas, por Marianna C. Slocum, «The Origin of Corn and other Tzeltal Myths», en Tlalocan, revista de fuentes para el conocimiento de las culturas indígenas de México (México: Casa de Tláloc, 1965), vol. I, pp. 1-7. La traducción al castellano ha sido preparada con base en la versión interlineal que acompaña al texto en lengua tzeltal. 
Tláloc o de sus servidores los tlaloqueh. Entre los mayas, las plegarias se dirigían a Chac y a Cocijo entre los zapotecas. También, como en un canto mixteca que aquí transcribiré, la impetración se hace llegar a «Nuestra Madre, Nuestro Padre» y a la vez a todos los «Grandes señores de la lluvia».

Otro testimonio de la persistencia de la palabra en Mesoamérica lo ofrecen los tres himnos - dos del ámbito náhuatl, uno prehispánico y otro reciente-, así como el que es composición de origen mixteca.

Himno sagrado prehispánico, entonado en México-Tenochtitlan

Bebedor de la noche, ¿por qué te ocultas?

Ponte tu ropaje de oro, revístete de la lluvia, oh mi Dios, dádiva de jades de agua: desciende y transforma al ahuehuete en plumas verdes de quetzal...

No perezca la tierna mata de maíz, mi corazón es esmeralda, tendrá sosiego mi corazón, nacerá el jefe de guerra.

Oh mi Dios, haya abundancia de maíz, la tierna mata ante ti se estremece, tiene fija en ti su mirada, hacia tus montañas, te adora.

Tendrá sosiego mi corazón, el hombre madurará, nacerá el jefe de guerra ${ }^{9}$.

${ }^{9}$ Himno sacro, transcrito por fray Bernardino de Sahagún de la tradición prehispánica, texto original preservado en la Biblioteca de la Real Academia de la Historia, Madrid. Una publicación del mismo: Angel María Garibay K., Veinte himnos sacros de los nahuas (México: UNAM, Instituto de Investigaciones Históricas, 1958), pp. 175-176. 
Canto de Oztocohcoyohco, 'La cueva horadada', cerca de Hueyapan, Morelos (tradición reciente)

Pasad al interior de la cueva, pasad con muchas flores y cantos, haced súplicas a todos los vientos, en el interior de la cueva.

Allí van entrando los venerados vientos.

Ante el rostro de los vientos, aquí sobre la tierra vamos pasando, nos ponemos de rodillas, llevamos una, dos antorchas, con uno, dos manojos de flores.

Venimos todos nosotros a hacer súplicas:

Que Tláloc nuestro dios

dé la lluvia al monte, y a los hijitos de la gente,

¡Oh todos vosotros, estimados señores!

iOh todos vosotros, venerados vientos! ${ }^{10}$

Canto mixteco, imprecatorio de la lluvia

Aquí vengo:

la tierra está seca.

Aquí vengo, oh Padre, aquí vengo, oh Madre,

a la casa de Nuestro Padre,

a la casa de Nuestra Madre.

Vengo con ofrendas

a la casa del gran señor de la lluvia, de la reverenciada lluvia

que posee el relámpago y el trueno.

Vengo a la casa del Señor de la lluvia, que vive en las alturas de los montes.

Grande es este día, hoy vengo a invocar

a todos los señores de la 1luvia.

Con fuerza invoco hoy

a los grandes señores de la 1luvia.

Oh, ivenid! ¡Recibid estas ofrendas!

${ }^{10}$ Canto de Oztocohcoyohco. Edición y versión del náhuatl de Miguel LeónPortilla (en Tlalocan, México, 1962, vol. IV, pp. 62-63). 
Las traemos en nuestras manos.

Aquí está preparada la estera, el asiento de la ofrenda, oh Padre nuestro, oh Madre nuestra.

Hoy vengo con ofrendas para que por esto caiga la lluvia. A vuestras manos llegan las velas, el copal (incienso). Venimos con flores en las manos, venimos con guirnaldas, trece sobre la estera, trece sobre el asiento, en la casa de la gran lluvia, en la casa de la gran lluvia, éstas vienen aquí sobre la estera, éstas vienen aquí sobre el asiento.

Aquí viene la resina del copal, aspiradlo, bebedlo, comedlo.

Aquí viene otra ofrenda, viene la sangre, bebedla, comedla, sobre la estera, el asiento, grande es este día. Aquí está, ¡bebed, comed! Aquí hago caer la resina en la cueva, adonde he venido con mis ofrendas, bebed esto, comedlo, vosotros grandes señores de la lluvia.

Grande es este día en el que habéis abierto vuestra casa. Aquí vengo, adonde vosotros traéis la salud, adonde vosotros concedéis la paz! ${ }^{11}$

\section{El ÁGUILA DE LA NACIÓN AZTECA}

Crónicas y cantares en lengua náhuatl describen la portentosa presencia del águila sobre un nopal (chumbera) en el lugar en que el dios de

${ }^{11}$ Texto recogido en mixteco de Guerrero por Leonhard Schultze Jena, Indiana III, Bei den Azteken, und Tlapaneken der Sierra Madre del Sur von Mexiko (Jena: Verlag von Gustav Fischer, 3 vols., 1933-1938), vol. 3, p. 87. 
los aztecas, Huitzilopochtli, había profetizado que sería residencia definitiva de su pueblo. E1 portento del águila se representa también en varios códices o manuscritos indígenas como los que ostentan los siguientes nombres: Mendoza, Aubin, Azcatitlan y otros más. En cambio, tradición más difícil de documentar es la que conserva el cronista del siglo XVI, de nombre ya español, pero que escribía en náhuatl, Cristóbal del Castillo. Según ese relato, el águila de los aztecas no sólo apareció en el lugar meta de su peregrinación, sino que vino acompañándolos a lo largo de la misma, hasta que al fin se posó en medio del gran valle, en el corazón de lo que llegaría a ser la gran ciudad de México.

Eco viviente de ese relato es el texto que ha conservado vivo, «aprendido de sus mayores», una persona contemporánea, cuya lengua materna es el otomí, el señor Ernesto Pérez Francisco, de Huehuetla, en el estado de Hidalgo. Recogido este testimonio hace unos cuantos años, es nueva muestra de la perduración en Mesoamérica de la palabra antigua que dejaron dicha los sabios y forjadores de cantos. Comencemos con el relato de la tradición prehispánica.

\section{La tradición en náhuatl sobre el águila que se posó en México}

Por dondequiera, en lugares difíciles, bosques, pedregales, fueron saliendo los mexicanos, porque en verdad los viene guiando el obrador de portentos. En águila se transformó [la hizo su nahual: alter ego], sobre ellos vuela con fuerza, los guía, en verdad así lo manifestó a su servidor Huitzilopoch, el que hace de señor de los mecitin. Le dijo:

- En verdad os guiaré, adondequiera que vayáis, como águila en lo alto me manifestaré con blancura, os hablaré con gritos adondequiera que vayáis; tan sólo contempladme y cuando vaya yo a acercarme allá, adonde me parezca bueno que vosotros os establezcáis, allí me posaré, allí me veréis, ya no volaré más. Así luego edificaréis allí mi altar, mi casa, mi lecho de hierba, donde yo [como águila] estaré erguido y allí toda la gente hará su casa, vosotros allí habréis de estableceros ${ }^{12}$.

Según este texto, el águila sólo se posó en el lugar bueno, es decir, grande, hermoso, donde habría de erguirse el templo mayor de los aztecas, en el futuro corazón de su ciudad. El relato moderno, conservado en lengua otomí, habla también del águila sagrada, guía de los aztecas. E1 águila hace varios intentos de posarse, extendiendo sus alas. Ello ocurrió

${ }^{12}$ Cristóbal del Castillo, Fragmentos de la obra general sobre la historia de los mexicanos, escrita en náhuatl. Edición de Francisco del Paso y Troncoso (Florencia: Tipografía de Salvador Landi, 1908), p. 55. 
en poblaciones como Tlaxco, Xicotepec y Huauchinango, en lo que es territorio del actual estado de Puebla. Pero en todos esos sitios no cupieron las alas del águila, que eran muy grandes. No fue sino hasta llegar al gran valle de México donde, en definitiva, pudo asentarse, extendiendo del todo sus alas. Allí, de acuerdo con el moderno testimonio otomí, iba a nacer un pueblo muy grande. El relato habla del modo como, con bejucos, los aztecas fueron entretejiendo grandes armazones, a modo de enormes canastos, enraizados en el fondo del lago. En el interior de dichos armazones echaron tierra. De este modo el pequeño islote iba a crecer. El texto hace así referencia a las que se conocen como chinampas, las célebres estructuras para ganar tierra al lago. Algunas de éstas, muy grandes, pueden contemplarse hasta hoy en Xochimilco, al sur de la ciudad de México, verdaderos jardines de flores circundados de canales. He aquí el texto, evocación de lo que dejaron dicho los ancianos.

\section{El águila sagrada que vivió hace mucho tiempo}

Un águila sagrada vivió hace mucho tiempo, descendió a Tlaxco. En una ocasión que se posó, extendió sus alas, pero al extenderlas no cupieron en ese llano. Por eso pensó que un pueblo chico no era suficiente para ella. Así que siguió adelante, se dirigió a Xicotepec y se posó allí. Cuando hubo llegado a Xicotepec, volvió a extender sus alas, pero en ese llano tampoco cupieron sus alas. Entonces pensó seguir hasta Huauchinango. Llegó a Huauchinango, se posó donde está el pueblo y extendió sus alas otra vez. El águila sagrada pensaba que cabría allí, pues el llano era grande. Pensando eso, extendió sus alas, pero no cupieron en el llano totalmente extendidas, pues el águila era muy grande.

Pensó entonces seguir a México. Había allí un nopal en medio de un lago. El águila extendió sus alas, y cupieron muy bien; podría dar la vuelta con sus alas extendidas.

Cuando la gente de ese lugar vio al águila, se quedó asombrada. - ¿Cómo es que llegó aquí el águila?, decían. Ellos nunca habían visto un águila tan grande como ésa. Fueron las gentes del lugar a verla donde se había parado, y la honraron. Entonces pensaron con respecto a ella: -De seguro fue determinado que llegara aquí esta águila tan grande en señal de que debe haber aquí un pueblo grande.

Entonces pensaron qué hacer en ese lugar donde se encuentra ahora la ciudad. De entre ellos unos pensaron encorvar bejucos [que crecían allí], que sirvieran de base a la ciudad de México donde se posó el águila. Extendieron los bejucos al nivel del agua, y entonces los entretejieron como el fondo de un canasto. Luego echaron tierra encima, 
mucha tierra, para que de ese modo pudieran algunos construir sus casas encima de ellos. La gente construyó allí sus casas, porque eso les hizo pensar el águila.

Luego la gente decidió seguir haciendo lo mismo poco a poco, es decir, ir extendiendo carrizos por todos los lados y vaciarle tierra. Y luego otros pensaron seguir haciendo lo mismo que habían hecho los primeros: extender los bejucos por todas partes. Una vez iniciado, siguieron haciéndolo para que la gente viviera allí. Por eso es que a veces tiembla la ciudad de México. Tiembla porque no es más que carrizo extendido sobre el agua, y no tierra verdadera.

Todo esto es lo que hizo la gente, y se lo inspiró el águila que se posó donde se irguió la ciudad de México ${ }^{13}$.

\section{El ÁRbOL SAGRADO DE DONDE PROVIENEN LOS MIXTECAS}

De la zona mixteca de Oaxaca existen varios manuscritos prehispánicos de contenido fundamentalmente histórico y genealógico. En ellos, los glifos (fechas, nombres de dioses, hombres y lugares, así como indicativos de otros objetos) se combinan con pinturas de personajes, animales, plantas y toda suerte de acontecimientos, incluso los referentes a los orígenes míticos de la nación mixteca. Sobre esto versan en particular la página 2 del 1lamado Códice Selden (conservado en la Biblioteca Bodleiana de la Universidad de Oxford) y la 37 del Códice Vindobonense (en la Biblioteca Nacional de Austria) ${ }^{14}$. Aquí atenderemos sólo a la página 2 del primero de estos manuscritos. Esta es su descripción, de abajo hacia arriba:

Una especie de vasija, representación de un río, está circundada por una tira terrestre, que remata a la izquierda en una cabeza de serpiente, y a la derecha, de tigre. Encima se mira un muro del que surge un árbol bastante complejo. Tiene en el centro un ojo, pues se ha tornado realidad portentosa. Sobre él cuelgan dos serpientes, de nubes y de estrellas. Por encima del árbol sale un personaje cuyo nombre nos lo da su glifo: «2-Hierba, Serpiente de Muerte». Ello octrre en un año 10-Caña, del

${ }^{13}$ Ernesto Pérez Francisco, «El águila sagrada que vivió hace mucho tiempo», texto en otomí y versión castellana en Artemisa Echegoyen y otros, Luces contemporáneas del otomí. Gramática del otomí de la Sierra (México: Instituto Lingüístico de Verano en coordinación con la Secretaría de Educación Pública, Dirección General de Educación a Grupos Marginados, 1979), pp. 35-37.

${ }_{14}$ Véase Códice Selden, reproducción facsimilar y comentario por Alfonso Caso (México: Sociedad Mexicana de Antropología, 1964). Introducción de O. Adelhofer (Graz, 1974). 
tiempo primordial. A ambos lados del árbol hay un sacerdote que, de un modo o de otro, con sus ceremonias, propicia la culminación de un portento: el nacimiento de los ancestros del pueblo mixteca que fueron concebidos dentro de un árbol.

Se conservan varios textos que aluden a lo que se representa en el códice. Citaré sólo un fragmento que muestra la importancia de la tra-

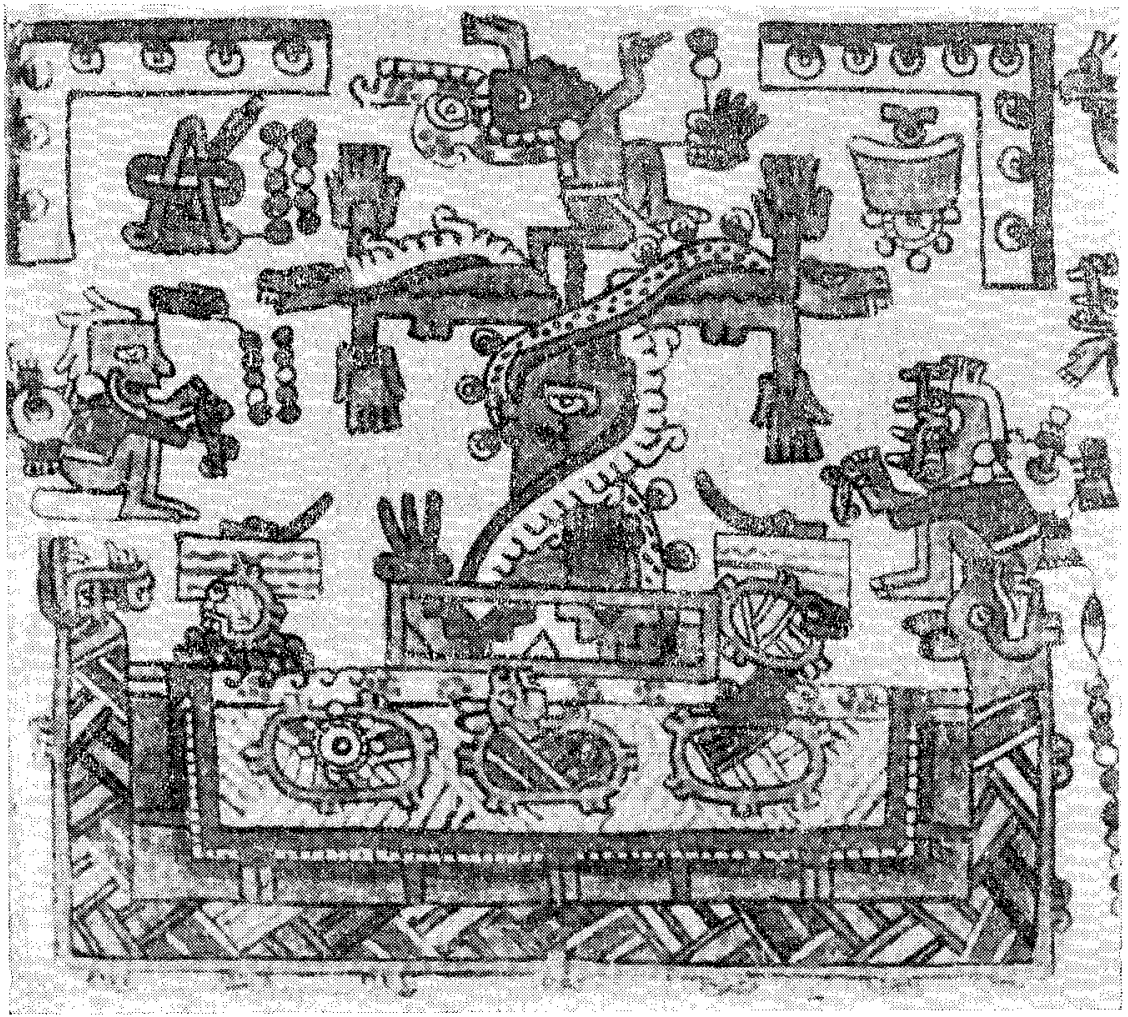

Códice Selden (Manuscrito mixteco prehispánico).

dición sistemática en relación con los códices. El testimonio lo obtuvo de los mixtecas, en el siglo xvi, el autor del Arte de la lengua mixteca, fray Antonio de los Reyes:

Vulgar opinión fue entre los naturales mixtecos que el principio de sus dioses y señores había sido en Apoala, pueblo desta Mixteca, que 
en su lengua llaman Yuta Tnoho, que es 'río de donde salieron los señores', porque decían haber sido desgajados de unos árboles que salían de aquel río, los cuales tenían particulares nombres. Llaman también a aquel pueblo Yuta Tooho, que es río de los linajes... ${ }^{15}$

Lo arraigado de esta tradición se confirma con un relato conservado hasta época muy reciente (1976) en lugares como San Juan y Santa Crux Mixtepec (Juxtlahuaca). He aquí lo que originalmente expresó en mixteco uno de los dos indígenas que hablaron acerca de esto:

Haré entrega de algunas palabras acerca de lo que sucedió hace mucho, según lo han referido los ancianos. Un hombre se fue a la montaña, hacia allá, hacia la montaña se marchó. Había estado ya ocho días cuando contempló un árbol sagrado, al que llaman Tnu Yuhndu. Se acercó a él y le hizo un agujero de un lado. Luego tuvo relaciones con él. Cuando habían pasado tres o cuarto meses, fue a mirarlo y vio que el árbol estaba hinchado. Contó los meses; cuando se completaron los meses, regresó y allí hizo un agujero en el estómago del árbol y vio que había dentro de él un hombrecillo; en su interior, en su interior había un pequeño hombre...

Cuando el hombrecillo creció, se hizo fuerte, muy fuerte. Adoró entonces a ese árbol, en verdad mucho. El árbol que estaba allí se hallaba como cabeza abajo. El fue y lo colocó con sus raíces donde deben estar. Así quedó colocado por él. El árbol creció y así nunca habría de secarse, nunca habría de morir... ${ }^{16}$

En la página citada del Códice Selden, libro indígena elaborado probablemente hacia el siglo xv, y también en la del Códice Vindobonense, tal vez más antiguo, está representado el núcleo de este relato.

La pervivencia de la antigua tradición, convertida aquí en comentario, que los especialistas no habían logrado, de las páginas de estos códices, es testimonio extraordinario. A casi medio milenio del momento en que, en las islas del Caribe, ocurrió el primer encuentro entre los hombres del nuevo y del viejo mundo, los textos citados - de entre otros muchos que

${ }^{15}$ Fray Antonio de los Reyes, Arte de la lengua mixteca (México: Casa de Pedro Balli, 1593). La cita está tomada del «Prólogo», 12 hojas sin numerar.

${ }^{16}$ Texto de la tradición indígena, comunicado en lengua mixteca por el señor Serapio Ramírez Ramos, del pueblo de Santa Cruz Mixtepec, Juxtlahuaca, Oaxaca. El relato fue a su vez repetido por el señor Basilio Gómez Bautista, también nativo mixteco, originario de San Juan Mixtepec, Juxtlahuaca, Oaxaca. El texto mixteco, transcrito por Thomas J. Ibach, ha sido incluido en Tlalocan, revista de fuentes para el conocimiento de las lenguas indígenas de México (México: Instituto de Investigaciones Históricas, 1980), vol. VIII, pp. 243-247. 
podrían aducirse- revelan que hay gentes en cuyo corazón perdura la antigua palabra de Mesoamérica. Nezahualcóyotl (1401-1472), sabio y poeta del México prehispánico, de algún modo entrevió esto, cuando dijo:

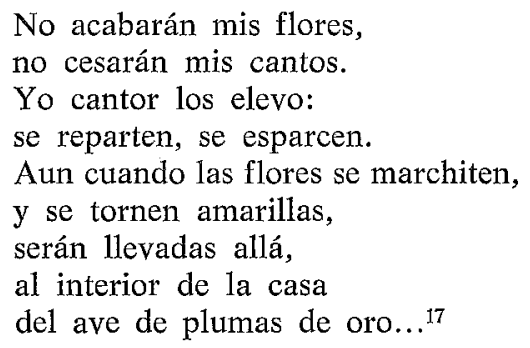

Las palabras de Nezahualcóyotl y de tantos otros forjadores de cantos, escudriñadores de realidades divinas y humanas - unos de nombre conocido y otros muchos anónimos-, hasta hoy perduran. Son flores y cantos de Mesoamérica, conservados en su lengua original y también traducidos —cada día en mayor número- al castellano y a otros idiomas de Europa y Asia. De esta suerte, por los cuatro rumbos del mundo, se valora y se escucha el mensaje de la palabra antigua y nueva del hombre de Mesoamérica.

${ }_{17}$ Manuscrito de Cantares Mexicanos, preservado en la Biblioteca Nacional de México, folio 16 v. Traducción del texto náhuatl de Miguel León-Portilla. 